\title{
A New Imaging Spectrometer for the Auroral Spectroscopic Studies
}

\author{
Hiroshi OKAMURA ${ }^{1}$ and Masaki EJIRI ${ }^{2}$ \\ ${ }^{1}$ University of Electro-Communication, Chofu-City, Tokyo 182, Japan \\ ${ }^{2}$ National Institute of Polar Research, Itabashi-ku, Tokyo 173, Japan
}

(Received September 28, 1991; Revised February 6, 1992)

\begin{abstract}
In order to study the detailed auroral spectral features that vary with a time, we have developed a new type of an auroral spectrometer which has a high time resolution. It can measure quantitatively a spectral apparent emission rate of aurora in a coordinate system of a wavelength and a spatial field of view of 72.6 degrees. A maximum time resolution, of course depending on an auroral luminous intensity, is 0.2 sec. Observations with this instrument were carried out at Syowa Station, Antarctica, in 1989 austral winter. Preliminary results show various different spectral characteristics of aurora which, some cases, vary rapidly with a time.
\end{abstract}

\section{Introduction}

Much valuable information has been obtained from optical images in the auroral studies. Especially in the auroral imageries by satellite observations, e.g., the ISIS 2 (ANGER et al., 1973; ShEPHERD et al., 1973; Lui et al., 1977), the Defense Meteorological Satellite Program (DMSP) spacecraft (RoGERS et al., 1974; EATHER, 1979; MENG et al., 1979; MENG and LUNDIN, 1986), the KYOKKO (KANEDA, 1979), the Dynamic Explorer 1 (FRANK et al., 1981; FRANK and CRAVEN, 1988), the VIKING (ANGER et al., 1987a, 1987b; SHEPHERD et al., 1987), the HILAT (MENG and HUFFMAN, 1984; BYTHROW et al., 1986), and the AKEBONO (OGUTI et al., 1990), plenty of global auroral images associated with the magnetospheric substorms have been provided. These techniques have been extended to the recent comet Halley mission (e.g., SAGDEEV et al., 1986; KEller et al., 1986). Groundbased auroral imaging instruments such as an all-sky camera (e.g., WINNINGHAM et al., 1973) and a TV camera (e.g., ONO et al., 1987; YАMAMOTO, 1988) also have been utilized in morphological auroral studies. However, changes in auroral spectral features associated with the magnetospheric substorms have not been satisfactorily clarified yet, since an active aurora at substorm expansion phase moves and changes its light intensity so rapidly that high spatial and time resolutions are required. We have developed a new two-dimensional auroral spectrometer that measures both wavelength and spatial auroral luminosity. (A spectroscopically resolved multichannel image camera developed by YOKOTA et al. (1988) uses the same method.) The instrument is composed of a spectroscope, an image intensifier (I.I.), and a CCD area sensor, together with a system control unit, a data processing unit and a gimbal system. This paper is to describe the principles of the instrument and observed examples of auroral spectrograms. 


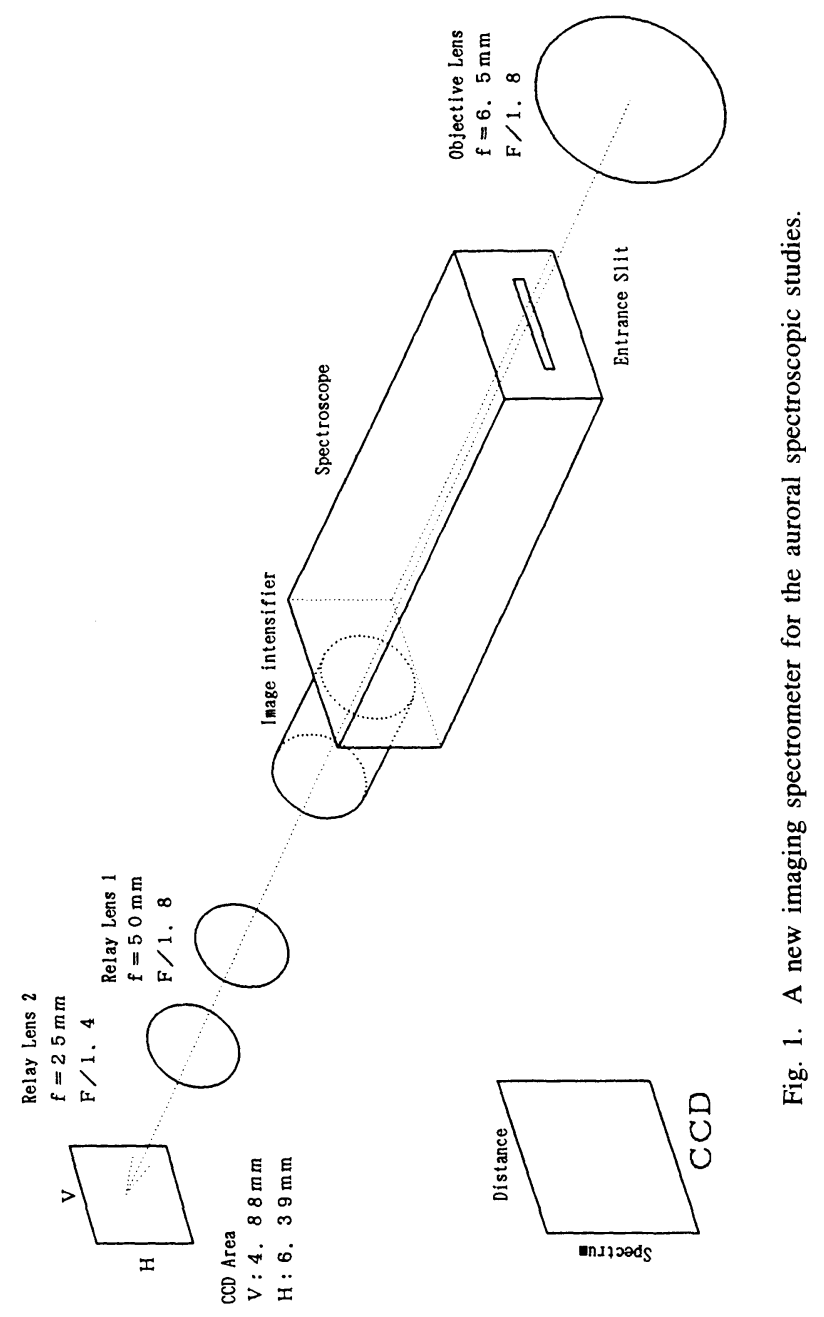


2. New Auroral Spectrometer System

\subsection{Optical and electrical systems}

The auroral spectrometer consists of a spectroscope with a reflective grating, an image intensifier (I.I.: V2025U-08), and a CCD (TCD-205C; inter line) area sensor. As shown in Fig. 1, the camera lens in front of an entrance slit of the spectroscope has a focal length of $6.5 \mathrm{~mm}$ and an F-number (inverse of an aperture ratio) of $\mathrm{f} / 1.8$. The entrance slit is $20 \mathrm{~mm}$ ( $9.8 \mathrm{~mm}$ effective) in length and 0 to $4 \mathrm{~mm}$ in width (variable). The I.I. is attached on the exit focal plane of the spectroscope. An auroral spectral-resolved image is amplified with the I.I. and focused on the CCD area sensor through two relay lenses; focal lengths of $50 \mathrm{~mm}$ and $25 \mathrm{~mm}$, and F-numbers of $\mathrm{f} / 1.8$ and $\mathrm{f} / 1.4$, respectively. The size of CCD sensitive area is $6.39 \mathrm{~mm}(\mathrm{H}$ : Horizontal $) \times 4.88 \mathrm{~mm}(\mathrm{~V}$ : Vertical $)$, and effective pixels are $376(\mathrm{H}) \times 488$ (V). The signals of vertical 4 pixels of original image area added to make one element of subpicture which consists of $376(\mathrm{H}) \times 61(\mathrm{~V})$ array. The resultant signals are fed to a correlative dual sample-hold amplifiers, whose output signal is proportional to the input and free from the CCD reset noise and current preamplifier $1 / f$ noise. The horizontal line of the CCD area sensor is aligned to be perpendicular to the entrance slit, that means the resolved spectrum consist with the horizontal line of the CCD image and its vertical line corresponds to the field of view (FOV) of 72.6 degrees. The used spectroscope in this system is a CT10 which installs the grating of 300 lines $/ \mathrm{mm}$, and its spectral width is $430 \mathrm{~nm}$, the spectral resolution $9.2 \mathrm{~nm}$ (slit width of $20 \mu \mathrm{m}$ ), the focal length $100 \mathrm{~mm}$ and the aperture ratio $\mathrm{f} / 3$. The successive image data are converted to 12-bit digital signal with a data processing unit, which combines the status data such as temperatures of a CCD, an I.I. and an electrical circuit, angle data of elevation and azimuth directions of the gimbal, a value of applied high-tension to the I.I., data sampling rate and exposure time, a center wavelength of measuring spectrum, a used spectroscope ID number, observation time (UT) and the synchronization words of FAF30C05 $(\mathrm{H})$. These status data are monitored by the micro computer, whereas digital

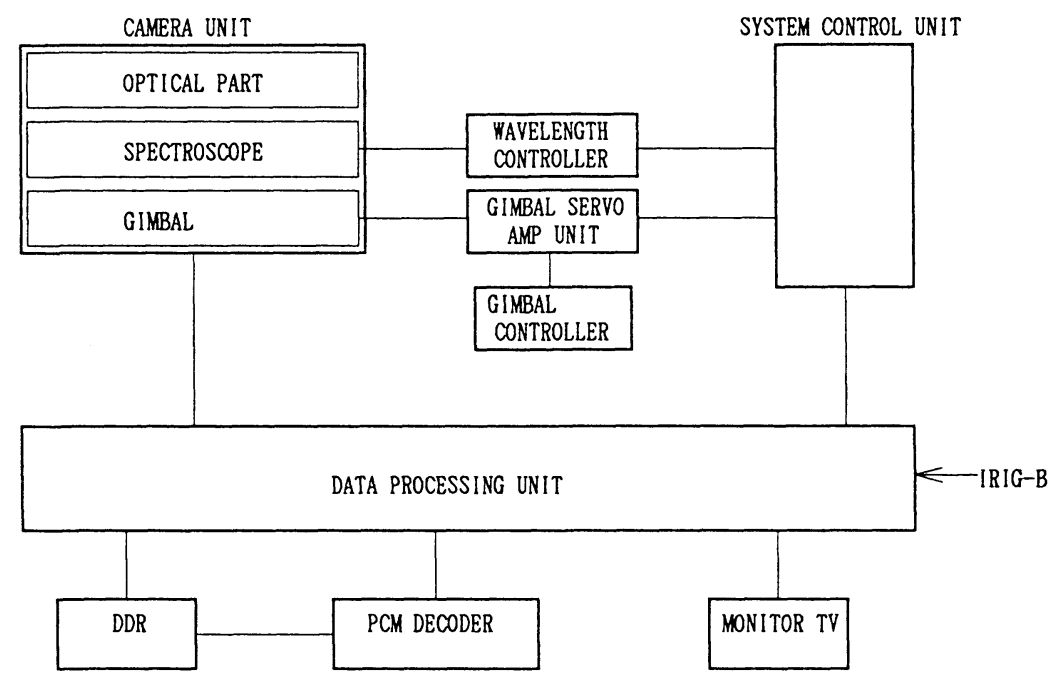

Fig. 2. A functional block-diagram of the system. 
signals by the PCM decoder EE4100. A wide-band data recorder M10le records the digital data stream, the resultant image data of which are converted into a video signal and monitored by a monochrome CRT display. The system functional block-diagram is illustrated in Fig. 2.

\subsection{Gimbal system}

A gimbal used in this system consists of a gimbal unit, a servo amplifier unit and its control box. The camera unit is mounted on a gimbal unit; its line of sight is changeable from 0 to 90 degrees in elevation and from -180 to +180 degrees in azimuth, controlled by a joystick on the control box. Their angular values are converted to 12-bit digital data, and sent to the data processing unit and the micro computer for display. The angular resolutions are 0.022 degrees/digit in elevation and 0.088 degrees/digit in azimuth.

\subsection{Instrument performance}

The spectral resolving power of this optical system is checked and calibrated with a lowpressure mercury-vapor lamp. A spectral response of the spectroscope CT10 of 300 lines $/ \mathrm{mm}$ grating with a slit width of $20 \mu \mathrm{m}$ gives a spectral resolution of about $9.2 \mathrm{~nm}$ (FWHM) for the entire range of wavelength from $300.3 \mathrm{~nm}$ to $732.5 \mathrm{~nm}$. Note that the observed spectrogram as an entire system shows a wider FWHM of about $18.6 \mathrm{~nm}$, due to the cotamination of the off-axis light source, the astigmatism of a used spherical mirror in the spectroscope, etc.

The sensitivity for spectral luminance is measured, using a plane light source which is produced by a halogen lamp with the collimation lens system and two light diffusion opal glasses. This source is calibrated with the NBS (National Bureau Standard) lamp. The output $E$ [volt] at a wavelength $\lambda[\mathrm{nm}]$ from the CCD through the optical system is expressed by

$$
E(\lambda)=q_{\mathrm{ph}}(\lambda) \cdot J(\lambda) \cdot G(V) \cdot \Omega \cdot R(\lambda) \cdot Q(\lambda) \cdot C \cdot \Delta \tau \cdot \Delta \lambda
$$

where $q_{\mathrm{ph}}(\lambda)$ [Joule/photon] $=h c /\left(10^{-9} \times \lambda\right), h=6.262 \times 10^{-34}$ [Joule.s] a Planck's constant, $c=2.998 \times 10^{8}\left[\mathrm{~m} / \mathrm{s}\right.$ ] the velocity of light, $J$ [photons $/ \mathrm{cm}^{2} \cdot \mathrm{s} \cdot \mathrm{str} \cdot \mathrm{nm}$ ] a spectral luminance, $G$ an anode current amplification factor of an image intensifier (I.I.) as a function of an applied high-tension $V$ to the MCP, $\Omega$ [str] a solid angle of an FOV for one pixel, $R$ a diffracting efficiency of the grating, $Q(\lambda)$ a quantum efficiency, $C$ [volt $\left./ \mathrm{Joule} / \mathrm{cm}^{2}\right]$ a sensitivity of the CCD and $\Delta \tau$ [s] an exposure time varying from $0.2 \mathrm{~s}$ to $25.6 \mathrm{~s}$ and $\Delta \lambda$ $[\mathrm{nm}]$ a spectral band width for one pixel. An amplification factor $G$ of I.I. is changeable from $4.0 \times 10^{2}$ at $V$ equal to $1.0 \mathrm{kV}$ to $7.69 \times 10^{6}$ at $1.9 \mathrm{kV}$. Note that $J$ corresponds to an aurora spectral apparent emission rate per unit solid angle (the transmission rate of the atmosphere being tacitly assumed to be 1). For the spectroscope CT10 of 300 lines $/ \mathrm{mm}$ with a center wavelength of $560 \mathrm{~nm}$, an exposure time of $0.8 \mathrm{~s}$, and a $G$ of $2.0 \times 10^{3}$ ( $V$ equal to $1.1 \mathrm{kV}$ ), the spectral response of this system is $559 \pm 43$ [Rayleigh/nm/digit] at $500 \mathrm{~nm}$ wavelength and the total dynamic range of MSB 8 bits out of 12 bits of data is from 2.2 to 140.0 [kilorayleigh/nm]. Figure 3 provides the luminance sensitivity of the total system of the spectrometer with the spectroscope CT10, for example. 


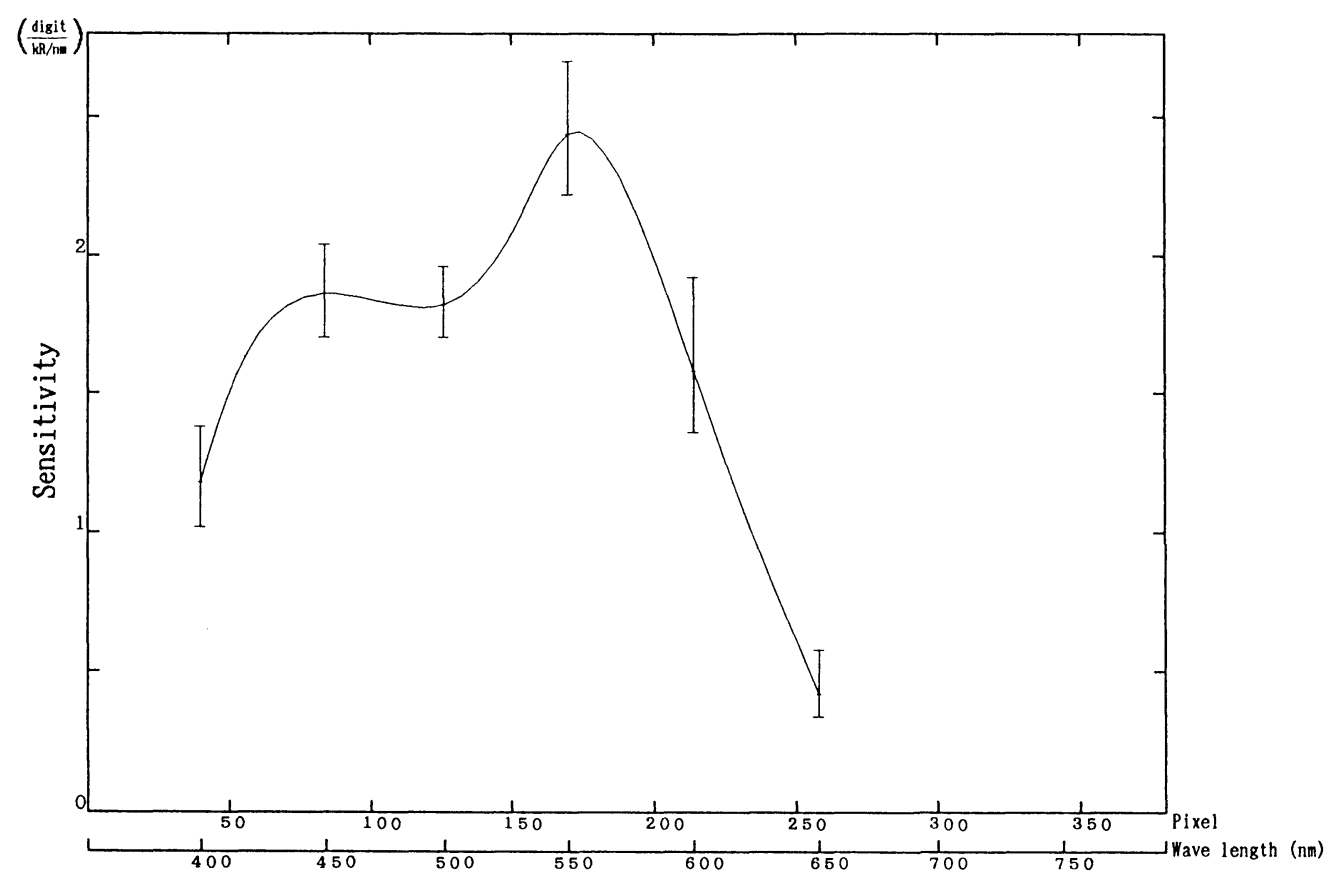

Fig. 3. Sensitivity curve of the total system of the spectrometer with the spectroscope CT10 $3001 / \mathrm{mm}$ (Center wavelength $572.6 \mathrm{~nm}$, entrance slit width $20 \mu \mathrm{m}$, exposure time $0.8 \mathrm{sec}$ ).

\section{Auroral Spectral Images}

A newly-developed auroral spectrometer reveals the new features of spectroscopic resolved auroral luminance which vary in space and time. Following data in this section are taken by the spectrometer with the spectroscope CT10 of 300 lines $/ \mathrm{mm}$ grating, a center wavelength of $556.0 \mathrm{~nm}$, an applied high-tension of 1150 volts (an amplification factor equal to $4.0 \times 10^{3}$ ) and an exposure time being changed as indicated in the data.

\subsection{Auroral spectrograms}

Firstly, a typical example is presented in order to understand a principle of this instrument and a new auroral spectrogram. Figure 4 shows a stable auroral arc extending from east to west, observed on June 8, 1989, at Syowa Station, Antarctica. A pseudo-colour scale is displayed in the right: blue is the lowest in intensity and white the highest. Figure 4(a) is a monochromatic $(557.7 \mathrm{~nm})$ all sky auroral image taken by the CCD TV camera (ONO et al., 1987) at 22:00:21.1 (UT). The optical center axis of the spectrometer is aligned to the zenith and the entrance slit the north-south direction. Therefore, a white line in the figure depicts a line of sight of the spectrometer, i.e., an FOV of 72.6 degrees. Figure 4(b) displays two sets of auroral spectrograms at 22:00:20.1 and 22:00:32.5 (and exposure time of 6.4 s), respectively. The ordinate scale of the top panel is proportional to a tangent of the zenith angle aligned N-S direction and the abscissa is a wavelength $(\mathrm{nm})$. The aberration of the 

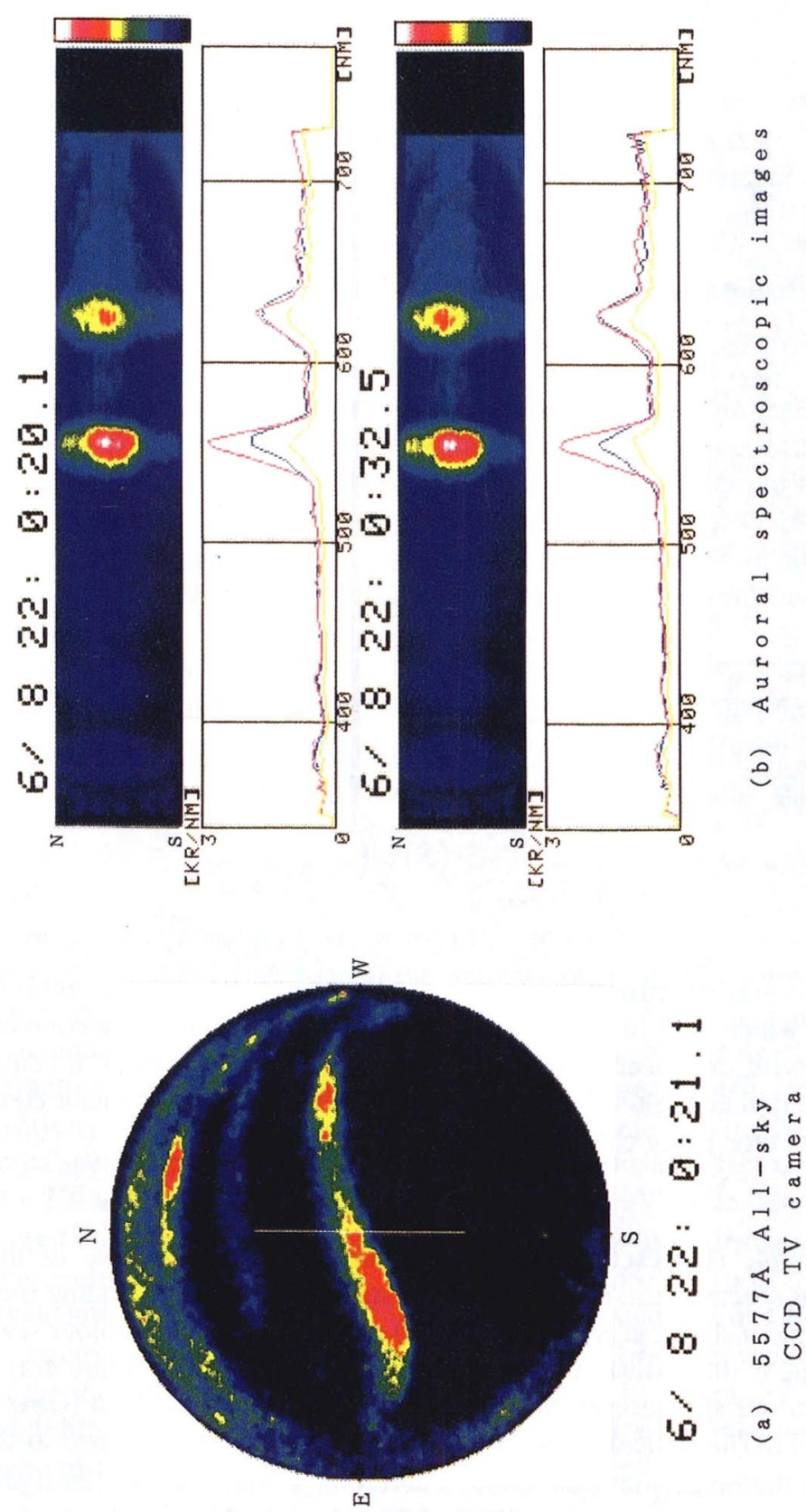

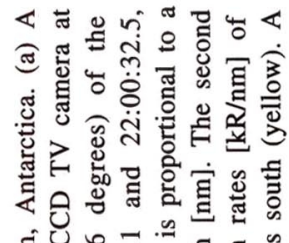
ฮี่

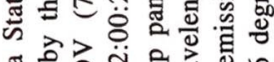
สำ 各雳证

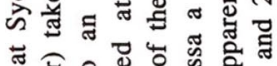

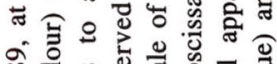

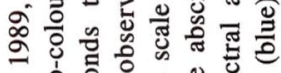

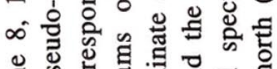

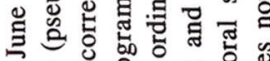

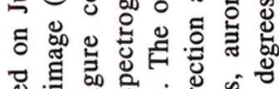

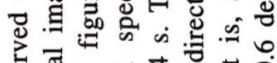

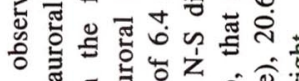

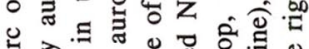
ส 券击

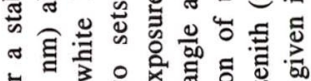

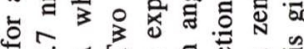

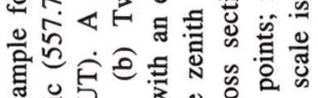

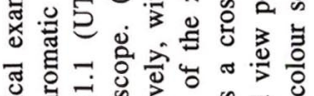

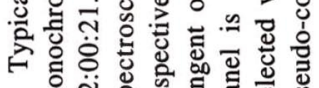

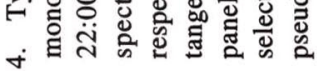
完 
(a) Diffuse Aurora

$6 / 7 \quad 1: 28: 12.5$

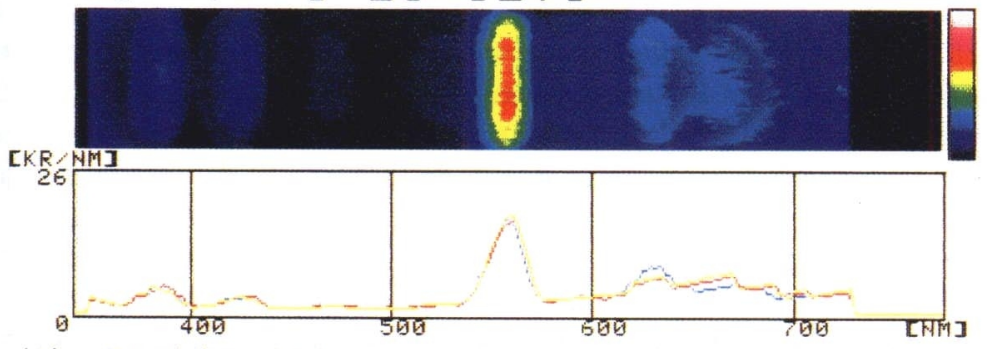

(b) Stable Arc

6. $821: 39: 37.6$

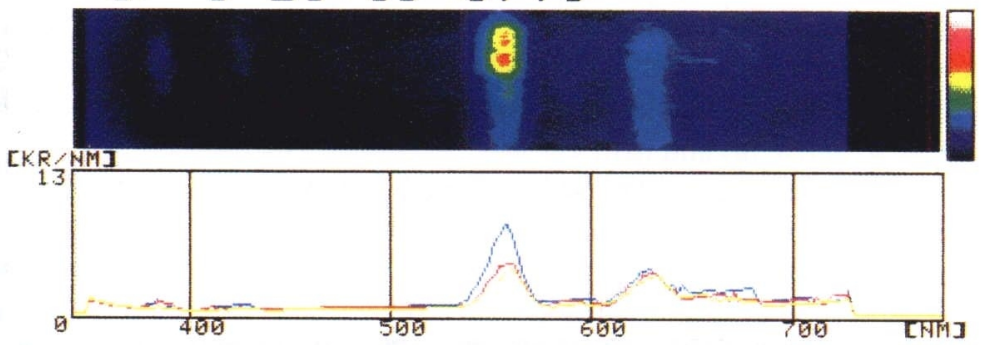

(c) Active Arc

$6 \% 823: 0: 1.7$

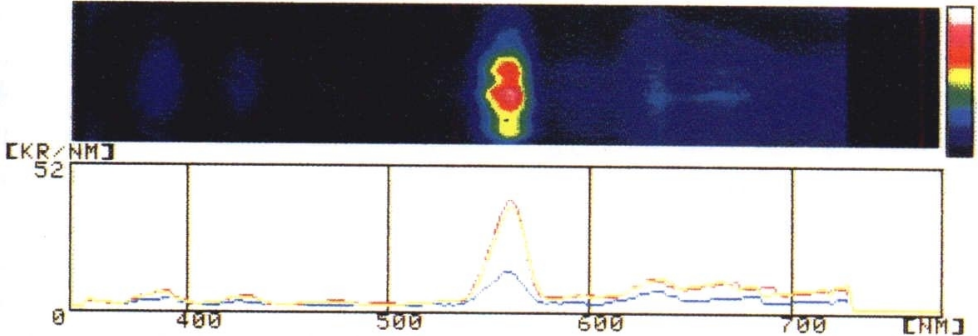

(d) Red Aurora

$6.92: 41: 21.8$

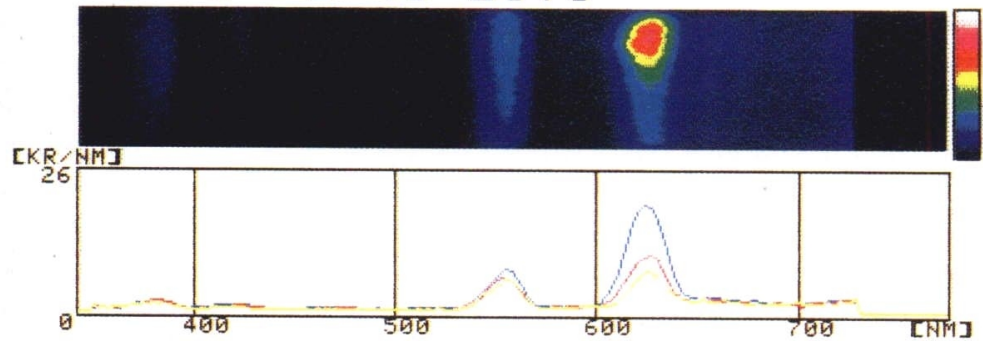

Fig. 5. Four different auroral spectrograms for (a) a diffuse aurora, (b) a stable arc, (c) an active arc and (d) a red aurora. Each display format is the same as that of Fig. 5(b). Optical axes are (a) $\mathrm{AZ}=0^{\circ}$ from the magnetic north and $\mathrm{EL}=20^{\circ}$, from the horizon, (b) $\mathrm{AZ}=65^{\circ}$ and $\mathrm{EL}=19^{\circ}$, (c) $\mathrm{AZ}=0^{\circ}$ and $\mathrm{EL}=$ $26^{\circ}$, and (d) $\mathrm{AZ}=90^{\circ}$ and $\mathrm{EL}=90^{\circ}$. Detailed descriptions are given in the text. 
image due to off-axis optical paths are corrected. The second panel is a cross section of the top panel, that is, auroral spectral apparent emission rates $[\mathrm{kR} / \mathrm{nm}]$ of selected view points of zenith (red line), 20.6 degrees north (blue) and 20.6 degrees south (yellow) versus a wavelength (the same format of this display is also applied to Fig. 5). As is evident, the oxygen green line $(557.7 \mathrm{~nm})$ is the most intense at the northward of the zenith, which just coincides with the location of the arc obtained in Fig. 4(a). This emission is associated with the oxygen red lines $(630.0-636.4 \mathrm{~nm})$ whose peak intensity is observed at a little northward of the peak of the green line presumably due to the difference in emission height. There are no other remarkable emission lines and/or bands observed in this case. This arc is so stable that the lower panel observed about $12 \mathrm{~s}$ later shows the almost identical spectrogram to the top panel.

\subsection{Spectroscopic classification of aurora}

There are several different auroral spectrograms observed in the austral winter season, 1989, at Syowa Station, out of which four typical types, i.e., a diffuse aurora, a stable arc, an active arc and a red aurora, are classified and their general characteristics are described in the followings (Figs. 5(a), (b), (c) and (d)).

(a) A diffuse aurora (Fig. 5(a) at 01:28:12.5 on June 7, an exposure time of $3.2 \mathrm{~s}$ ):

The auroral emission spreads over the entire field of view, that is, homogeneous in space. The most intense emission is at the oxygen green line $(557.7 \mathrm{~nm})$, associated with the $\mathrm{N}_{2}{ }^{+}$1NG $(0,1)$ band $(427.8 \mathrm{~nm})$, the $\mathrm{N}_{2}{ }^{+} 1 \mathrm{NG}(0,0)$ band $(391.4 \mathrm{~nm})$, and the $\mathrm{N}_{2}$ 1PG broad band centered around 1PG $(5,2)$ band $(670.5 \mathrm{~nm})$ emissions. The weak peak in intensity around $630 \mathrm{~nm}$ is due to the oxygen red lines $(630.0-636.4 \mathrm{~nm})$.

(b) A stable arc (Fig. 5(b) at 21:39:37.6 on June 8, an exposure time of $3.2 \mathrm{~s}$ ):

As is explained in the previous example of Fig. 4(b), the spatial extent of a stable arc is confined in the specific area of a field of view, and the most intense emission is at the oxygen green line together with the oxygen red lines. The weak $\mathrm{N}_{2} 1 \mathrm{PG}$ band emissions are also observable. Other emissions are very weak as is evident in the figure. Note that the scale of an ordinate of the second panel, i.e., a spectral intensity, is a half of that of Fig. 5(a).

(c) An active aurora (Fig. 5(c) at 23:00:01.7 on June 8, an exposure time of 1.6 s):

The light emission of this active aurora is so strong that an exposure time is reduced by half and the ordinate of a spectral intensity is changed to be twice of that of Fig. 5(a). There observed two arcs of the strong oxygen green line within a field of view. The characteristics of other emissions are almost the same as the case of a diffuse aurora except for the limited spatial extent of an active aurora.

(d) A red aurora (Fig. 5(d) at 02:41:21.8 on June 9, an exposure time of $3.2 \mathrm{~s}$ ):

This is a spatially confined red aurora which is characterized by the strong oxygen red lines emission compared with the weak oxygen green line emission that is, on the contrary, the strongest emission for the previous three types of aurora. But, the spectral intensity of this oxygen green line emission is almost the same as that of a stable arc. Other emissions observed in the previous cases are very weak but still having intensities detectable with this spectrometer.

\subsection{Time and spatial variations of auroral spectra}

Though there exist the distinct "static" characteristics of auroral spectra corresponding to different types of aurora, they change their spectral features with time and space. These dynamical behaviors are of the utmost importance and basic to study the physical processes 
and mechanisms of aurora. As is depicted below, the essential points are that the luminosities of all emission lines and bands do not vary in the same manner.

Figure 6 demonstrates the time-spatial variations of luminosities for selected emission lines/bands of $391.4 \mathrm{~nm}, 427.8 \mathrm{~nm}, 557.7 \mathrm{~nm}$ and $630.0 \mathrm{~nm}$, which are deduced from a spectrogram (an exposure time of $3.2 \mathrm{~s}$ ) for a stable arc observed from 21:30:07.9 to 21:39:40.8 (a time interval of about 10 minutes) on June 8, 1989. The upper 4 panels show the spatial (the ordinate being a field of view as same as Fig. 5) and time (a scale of the abscissa being given in the lowest in minute) changes in each emission luminosity. The second panel from the bottom shows the auroral apparent emission rates [kR] of 4 emission lines at the center of the field of view, i.e., a cross section in the middle of each panel. The gross features of the spectrum suggest that this is a case of stable arc as discussed in Fig. 5(b). And, a noticeable nature of this aurora is, as is evident in the figure, strong fluctuations in intensity of the oxygen green line of $557.7 \mathrm{~nm}$ as if the intense auroral streams are intermittently passing across the field of view. Also, the intensities for $\mathrm{N}_{2}{ }^{+} 1 \mathrm{NG}$ bands $(391.4 \mathrm{~nm}$ and $427.8 \mathrm{~nm}$ ) show the same time-variation as that for $557.7 \mathrm{~nm}$ though the intensities are weak. As for oxygen red line $(630.0 \mathrm{~nm})$, it does not always follow the other emissions. The lowest panel represents the intensity ratios of $391.4 \mathrm{~nm}$ (light blue), 557.7 $\mathrm{nm}$ (dark blue) and $630.0 \mathrm{~nm}$ (orange) luminosities relative to that of $427.8 \mathrm{~nm}$. There is no noticeable change in the ratio for $391.4 \mathrm{~nm}$ to $427.8 \mathrm{~nm}$, that is, almost constant during this time period. This suggests that the same source presumably produces both of these emissions. The ratio for $630.0 \mathrm{~nm}$ to $427.8 \mathrm{~nm}$ show some irregular variations in time, but is not so remarkable compared to that of oxygen green line $(557.7 \mathrm{~nm})$.

Another example illustrated in Fig. 7 (the display format is exactly the same as that of Fig. 6, an exposure time $6.4 \mathrm{~s}$ and the optical axis at zenith, the field of view being aligned $\mathrm{N}-\mathrm{S}$ direction) is for a diffuse aurora observed from 01:58:39.1 to 02:08:47.1 on June 5, 1989. The intensities at the zenith for $391.4 \mathrm{~nm}$ and $630.0 \mathrm{~nm}$ keep constant, whereas those for $557.7 \mathrm{~nm}$ and $427.8 \mathrm{~nm}$ in the latter part of this time interval show auroral pulsations with a period of about $12 \mathrm{~s}$.

\section{Concluding Remarks}

A new imaging auroral spectrometer, which measures quantitatively an auroral spectral apparent emission rate in space and in wavelength with a high time resolution, was successfully developed and utilized to auroral spectroscopic observations carried out at Syowa Station, Antarctica, in 1989 austral winter. Various auroral spectrograms obtained give their distinct different characteristics corresponding to different types of aurora, i.e., this preliminary study reveals, at least, 4 types of auroral spectrograms for a diffuse aurora, a stable arc, an active aurora and a red aurora. In addition to their fine spatial structures varying in time, the luminosities for different emissions change their intensities in different manners, suggesting a time-variation of the energy distribution of precipitating auroral particles.

As mentioned previously, to investigate the physical processes and mechanisms of aurora, it is essential to understand dynamical change in spectrum of aurora with space and time. Though these results given in this study are preliminary, the new spectrometer will be very useful for this purposes. Detailed data analyses and their results will be appeared in a separate paper. 


\section{$6 / 8 \quad 21: 30: 7.9 \quad 6 / 8 \quad 21: 39: 40.8$}
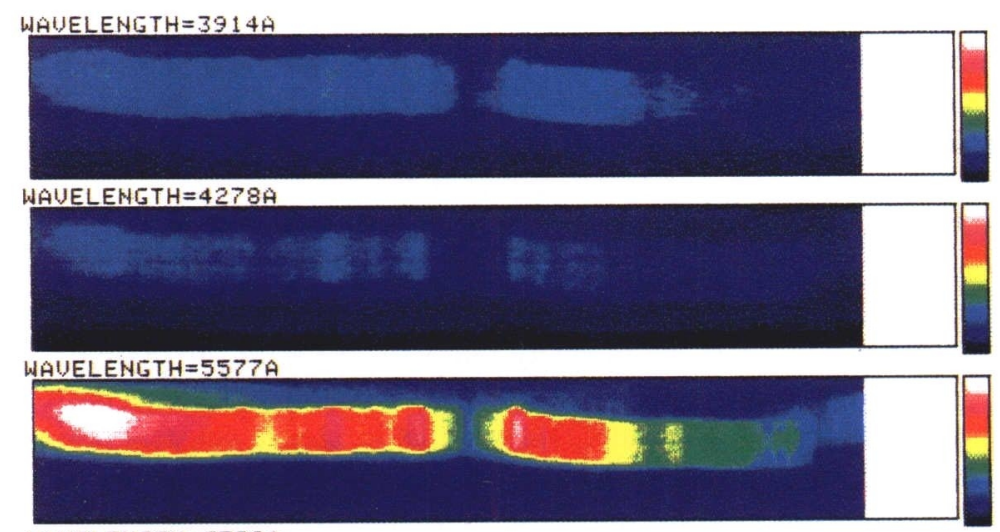

WAUELENGTH $=63099$
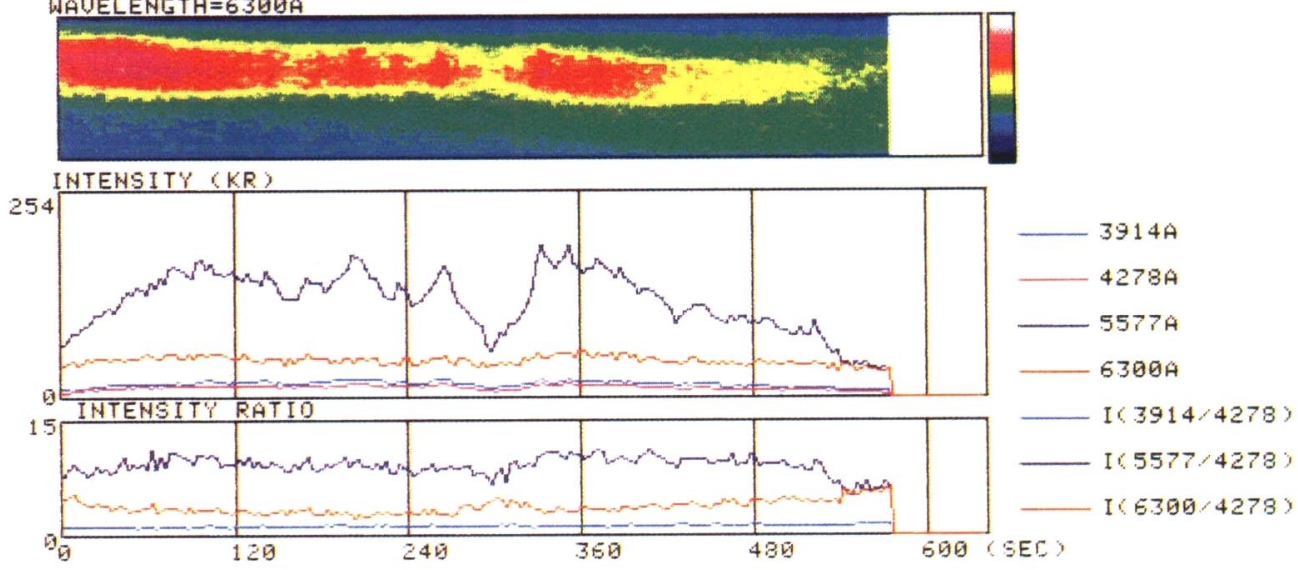

Fig. 6. Time-spatial variations in luminosity for selected emission lines/bands of $391.4 \mathrm{~nm}, 427.8 \mathrm{~nm}$, $557.7 \mathrm{~nm}$ and $630.0 \mathrm{~nm}$, which are deduced from a spectrogram for a stable arc observed from 21:30:07.9 to 21:39:34.4 on June 8, 1989. The upper 4 panels are spatial and time changes in each emission luminosity. 5th panel shows the spectral intensities at the center of the field of view. The lowest panel represents the intensity rations of emission luminosities relative to that of $427.8 \mathrm{~nm}$. The conditions of the spectroscope is the same as the case of Fig. 5(b). 


\section{$6 / 5 \quad 1: 58: 39.1 \quad 6 / 5 \quad 2: 8: 47.1$} WAUELENGTH $=3914 \mathrm{~A}$

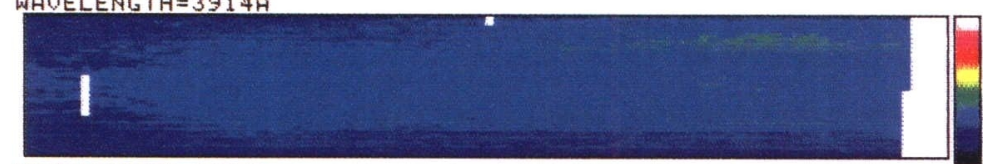

WAUELENGTH $=4278 \mathrm{~A}$

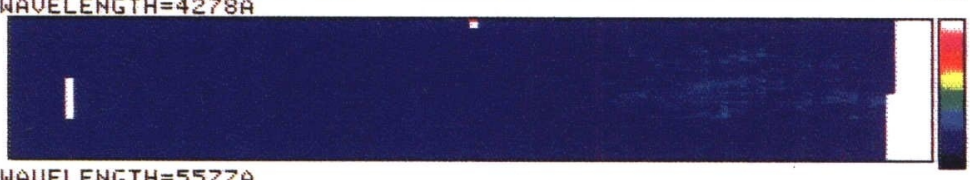

WAUELENGTH $=5577 \mathrm{~A}$
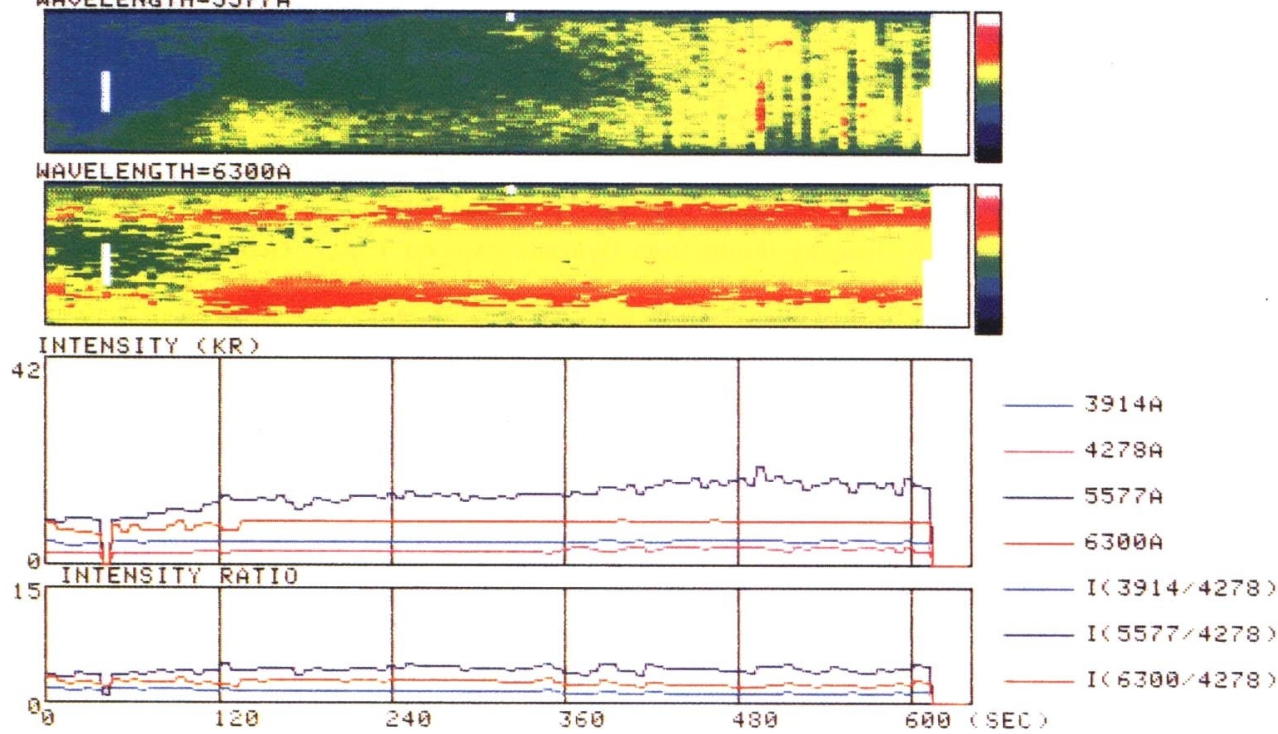

Fig. 7. The same display as Fig. 6 for a diffuse aurora observed from 01:58:39.1 to 02:08:47.1 on June 5, 1989. (An exposure time is $6.4 \mathrm{~s}$ and the optical axis is at zenith, the field of view being aligned $\mathrm{N}$ S direction.) 
This work was supported by the National Institute of Polar Research (NIPR), Japan. Authors express their thanks to Prof. T. Yoshino, Univ. Electro-communication, and Prof. T. Hirasawa, NIPR, for their valuable comments. The observations with the spectrometer were carried out during the 30th Japanese Antarctic Research Expedition at Syowa Station, Antarctica. Thanks are also due to Dr. T. Yokota, Ehime Univ., who kindly made an absolute calibration of the instrument with a standard (NBS) lamp. The authors wish to thank Mr. Y. Kameda and Mr. K. Tuno (TOSHIBA Corp.) for their contributions to the spectrometer design and fabrication. Data analysis was performed at the Information Science Center, NIPR.

\section{REFERENCES}

ANGer, C. D., T. Fancott, J. McNally, and H. KeRR, ISIS-II scanning auroral photometer, Appl. Opt., 12, 1753-1766, 1973.

Anger, C. D., S. K. Baybey, A. Lyle Broadfoot, R. G. Brown, L. L. Cogger, R. Gattinger, J. W. Haslett, R. A. King, D. J. McEwen, J. S. Murphree, E. H. Richardson, B. R. Sandel, K. Smith, and A. Vallance Jones, An ultraviolet auroral imager for the Viking spacecraft, Geophys. Res. Lett., 14, 387-390, 1987a.

Anger, C. D., J. S. Murphree, A. V. Jones, F. R. Harris, J. W. Haslett, E. J. Llewellyn, J. C. McConnel, D. J. McEwen, E. H. Richardson, G. Rostorker, B. R. SANdel, G. G. Shepherd, D. Venkatesan, D. D. Wallis, and G. Witt, Scientific results from the Viking ultraviolet imager: an introduction, Geophys. Res. Lett., 14, 383-386, 1987b.

Bythrow, P. F., M. A. Doyle, T. A. Potemra, L. J. Zanetti, R. E. Huffman, C.-I. Meng, D. A. Hardy, F. J. Rich, and R. A. HeElis, Multiple auroral arcs and birkeland currents: evidence for plasma sheet boundary waves, Geophys. Res. Lett., 13, No. 8, 805-808, 1986.

EATHeR, R. H., DMSP Calibration, J. Geophys. Res., 84, 4134-4144, 1979.

Frank, L. A. and J. D. Craven, Imaging results from Dynamic Explorer 1, Rev. Geophys., 26, 249-283, 1988.

Frank, L. A., J. D. Craven, K. L. Ackerson, M. R. English, R. H. Eather, and R. L. Carovillando, Global auroral imaging instrumentation for the Dynamic Explorer mission, Space Sci. Inst., 5, 369$393,1981$.

KANeda, E., Auroral TV observation by KYOKKO, Proc. International Workshop of Selected Topics of Magnetospheric Physics, Tokyo, pp. 15-19, 1979.

Keller, H. U., C. Arpigny, C. Barbieri, R. M. Bonnet, S. Cazes, M. Coradini, C. B. Cosmovici, W. A. Delamere, W. F. Huebner, D. W. Hughes, C. Jamar, D. Malaise, H. J. Reistema, H. U. Schmidt, P. Seige, F. L. Whipple, and K. Wilhelm, First Halley multicolour cameraimaging results from Giotto, Nature, 321, 320-326, 1986.

Lui, A. T. Y., D. Venkatensan, C. D. Anger, S.-I. Akasofu, W. J. Heikkila, J. D. Winningham, and J. R. BURRows, Simultaneous observations of particle precipitations and auroral emissions by the ISIS2 satellite in the 19-24 MLT sector, J. Geophys. Res., 82, 2210-2226, 1977.

Meng, C.-I. and R. E. HufFMAn, Ultraviolet imaging from space of the aurora under full sunlight, Geophys. Res. Lett., 11, 315-318, 1984.

MenG, C.-I. and R. Lundin, Auroral morphology of the midday oval, J. Geophys. Res., 91, 1572-1584, 1986.

Meng, C.-I., B. Mauk, and C. E. McIlwain, Electron precipitation of evening diffuse aurora and its conjugate electron fluxes near the magnetospheric equator, J. Geophys. Res., 84, 2545-2558, 1979.

Oguti, T., E. Kaneda, M. Ejiri, S. Sasaki, A. Kadokura, T. Yamamoto, K. Hayashi, R. Fuji, and K. MAKITA, Studies of aurora dynamics by auroral-TV on the Akebono (EXOS-D) Satellite, J. Geomag. Geoelectr., 42, 555-564, 1990.

Ono, T., M. Ejiri, and T. Hirasawa, Monochromatic auroral images observed at Syowa Station, in Antarctica, J. Geomag. Geoelectr., 39, 65-95, 1987.

Rogers, E. H., D. F. Nelson, and R. C. Savage, Auroral photography from a satellite, Science, 183, 951952, 1974.

Sagdeev, R. Z., J. Blamont, A. A. Galeev, V. I. Moroz, V. D. Shapiro, V. I. Shevchenko, and K. Szego, Vega spacecraft encounters with comet Halley, Nature, 321, 259-266, 1986. 
Shepherd, G. G., T. FAncott, J. McNally, and H. S. Kerr, ISIS-II atomic oxygen red line photometer, Appl. Opt., 12, 1767-1774, 1973.

Shepherd, G. G., C. D. Anger, J. S. Murphree, and A. Vallance Jones, Auroral intensifications in the evening sector observed by the Viking ultra violet imager, Geophys. Res. Lett., 14, 395-398, 1987.

Winningham, J. D., S.-I. Akasofu, F. Yasuhara, and W. J. Heikkila, Simultaneous observations of auroras from the south pole station and of precipitating electrons by ISIS 1, J. Geophys. Res., 78, 6579$6594,1973$.

Yамамото, T., On the temporal fluctuations of pulsating auroral luminosity, J. Geophys. Res., 93, 897$911,1988$.

Yokota, T., S. Sasaki, N. Kawashima, M. Hoshi, and S. Teir, Development of a spectroscopically resolved multichannel image camera for a sounding rocket and satellite, Rev. Sci. Instruments, 59, No. 59, 2232-2234, 1988. 